\title{
CONDICIÓN SEMÁNTICA DE LAS PALABRAS EN RELACIÓN CON LAS MODALIDADES PARATÁCTICAS E HIPOTÁCTICAS DE SU PUESTA EN DISCURSO
}

\author{
ESTANISLAo RAMÓN TRIVES \\ Universidad de Murcia \\ trives@um.es
}

\begin{abstract}
Resumen
This paper deals with the phylogenetic and ontogenetic origin of the paratactic and hypotactic utterances in Spanish, so with the cognitive foundation of their argumentative-discursive perfornances.
\end{abstract}

1. Partimos del principio, para esta reflexión, de que las palabras significan y de que su significado tiene una virtualidad utópico-referencial ineludible en cuanto aviso de caminantes, monumento o, si se quiere, memorial de la experiencia humana filogenética y ontogenéticamente habida en una comunidad hablante, en cuanto "precipitado de experiencia humana", al decir de don Miguel de Unamuno, o en cuanto "interiorización" o "vistas" de las cosas, al modo orteguiano de presentar la realidad cultural que representa una lengua dada.

Nos basamos en la Retórica, de Aristóteles, III, 5-9, para hacer ver cómo el comportamiento verbal se organiza de acuerdo con determinadas estrategias y tácticas discursivas, todas ellas fundamentadas en la condición significativa de las palabras. La necesaria organización del comportamiento verbal exige la selección de unidades significativas o palabras plenas en un determinado orden de articulación discursiva y con elementos orientadores del sentido de los significados verbales en distinto grado, desde prácticas asindéticas, por voluntad expresiva dada la contraposición evidente o elementalidad de los segmentos verbales proferidos o por voluntad de no cerrar el sentido de un discurso dado por el carácter abierto de lo que se pretende decir - caso de los escritos de Heráclito-, hasta las prácticas polisindéticas, donde se matiza y perfila hasta el más pequeño de los sentidos de los significados verbales seleccionados en un discurso dado.

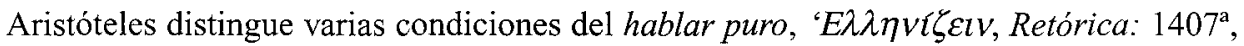
20:

Este trabajo se inscribe dentro del Proyecto "Construcciones paratácticas en español. Modelos cognitivos y procesos de tipología sintagmática" del Programa Séneca 2000 de la Comunidad Autónoma de la Región de Murcia.

ELUA, 17, 2003, págs. 547-557 
$-1 .^{\text {al: }}$ conjunciones, si se contraponen delante o detrás una de otra, según corresponde...Es preciso que se correspondan entre sí mientras dura el recuerdo, y que ni estén demasiado separadas ni ninguna conjunción corresponda antes que otra conjunción exigida... Una condición, pues, es el buen manejo de la conjunciones;

-2 . $^{\text {a: }}$ hablar con palabras propias, y no con términos universales (ya sean términos generales $\mathrm{y} / \mathrm{o}$ abstractos o perífrasis);

-3 a.: $^{\text {a }}$ no servirse de palabras ambiguas, a no ser que se prefiera lo contrario, lo cual se hace cuando no hay nada que decir y se finge decir algo....porque el circunloquio deslumbra en su abundancia;

-4.a: distinguir los géneros de las palabras, masculinas, femeninas y objetos;

-5.': expresar con exactitud lo múltiple y lo poco y lo uno.

La condición general que establece Aristóteles (ibid.) se centra plenamente en la salvaguarda inequívoca de condición significativa de las palabras:

En general es preciso que sea legible lo escrito, y bien pronunciable; lo cual es una misma cosa. Tal consiguen las muchas conjunciones, $<y$ no las pocas $>$ ni lo que no se puede puntuar fácilmente, como los escritos de Heráclito; porque buen trabajo es puntuar a Heráclito, por la oscuridad de adónde corresponde cada palabra, si a lo de antes o a lo de después... También hace cometer solecismo el no poner lo que conviene a ambos términos si se unen; por ejemplo, para ruido y color, ver no es común, pero percibir sí. Es oscuro el estilo si no terminas de decir algo antes, cuando vas a intercalar muchas cosas en medio.

La base de todo ello está en la selección de las palabras, según se señala en Aristóteles, Retórica: III 2,28:

-Como es de nombres y verbos de lo que el discurso se compone, y como los nombres tienen tantas especies como hemos visto en los libros Sobre poética [cap. 21], de entre éstos los compuestos inusitados y los neologismos hay que usarlos pocas veces y en pocos lugares..., <porque> desvían de lo adecuado a lo demasiado elevado;

-El nombre específico y el corriente y la metáfora es lo único que conviene para el estilo de los discursos en prosa sencilla. La prueba es que sólo de éstos se sirven todos, ya que todos hablan con metáforas, con los nombres corrientes y con los específicos, de manera que si uno hace bien su discurso, resultará algo extraño, como dijimos, y cabe que pase el arte desapercibido y el estilo sea claro. De los nombres, los equívocos le son útiles al sofista, pues en ellos están sus artimañas; los sinónimos, al poeta, los.

2. Pero la puesta en discurso hacia donde apuntan las observaciones aristotélicas relativas a la operación verbal se hace con palabras, pero no se reduce a ellas, dado que si las palabras son aptas para ser encaminadas hacia cualquier referente, en función de la memoria o concreción de experiencia humana que suponen para cualquier hablante, es lo cierto que reciben en el discurso una necesaria metaforización o transformación, siquiera sea tan fugaz como el discurso momentáneo de cualquier decir, de lo general a lo particular, que a su vez hace entrar al proceso ontológico-verbal de cualquier hablante en el proceso complementario de lo particular a lo general, en cuanto a disponibilidad de otros decires, en un ininterrumpido vaivén de la convivencia verbal humana, que da cauce obligado al comportamiento socio-semiótico en su integridad, dado que los tensemas de particularización 
y generalización que tan acertadamente diseña G. Guillaume no tienen otro fundamento, como por otra parte las observaciones de Aristóteles en su Retórica, Poética, Sobre la interpretación, etc., etc., o las de Platón en su República, El diálogo de Cratilo, El Banquete, etc., no tienen más sentido que su orientación o condicionamiento al mundo extraintraverbal de la percepción intelectiva de los referentes o marco sociosemiótico integrado del comportamiento del hombre en una sociedad dada.

Por eso hay que entender en su justo sentido a S. Mallarmé (1945:366) cuando dice que "parler n'a trait à la réalité des choses que commercialement", puesto que las palabras siempre tienen que ver con la realidad de las cosas, si bien la percepción intelectiva, intuitiva, en cuanto significado o noción pura de la realidad de las cosas que son nuestras palabras, como ha demostrado brillantemente Ramón Trujillo (1998), no coincide con cosa concreta alguna.

Pero de ello no se puede inferir que haya que prescindir de la a mi juicio ineludible respectividad utópico-referencial del significado de las palabras, ni filogenética ni ontogenéticamente, en cuanto memoria o "precipitado de experiencia humana", al decir de don Miguel de Unamuno, o, como indica Mallarmé (ib.: 366), "une allusion", "quelque idée". $Y$ es que las palabras siempre tienen que ver con la realidad de las cosas, pero no siempre de la misma manera; de lo contrario, mal podrían tener que ver con la realidad de las cosas comercialmente, dado que ex nihilo nihil fit. En efecto, unas veces las palabras de la operación verbal se afirman como palabras por generalización esencializadora, caso del decir poético, que se alimenta de la generalización arquetípica, "la notion pure", como explica el propio Mallarmé (ibid.:368), sobre todo en el siguiente texto: "Je dis: une fleur! Et [...] musicalement se lève, idée même et suave, l'absente de tous bouquets" en cualquiera de sus formas, sinonímica-como muy agudamente señala Aristóteles-, en línea con la creación metafórica -en lo que conviene todo hablar, según lo indicado por Aristóteles, supra: "ya que todos hablan con metáforas, con los nombres corrientes y con los específicos"; o se afirman como palabras por particularización individualizadora o unívoca, caso del decir comercial -en la justa apreciación de Mallarmé-, que se alimenta de la particularización en cualquiera de sus formas desde la identificación de la clase al individuo a los que apunta o puede apuntar el significado de las palabras, pues, en efecto, la particularización no es posible sin la generalización previa.

En efecto, como señalaba L. J. Prieto, identificar implica clasificar, identificar cualquier referente no es hacedero sino con referencia a su clasificación de acuerdo con determinadas características aplicables a cualquier referente que posea o soporte dichas características, y desde ellas se le adscribe a una clase referencial por la fuerza y virtud de la operación verbal, que no es ex nihilo, sino desde la contrarreferencia concreta que presuponen las palabras, que pueden ser aplicadas a esto o a lo otro, precisamente porque no son ni esto ni lo otro.

Lo cual fue lapidariamente expuesto por Antonio Machado (Obras. Poesía y prosa: 780 782, en su excelente comentario "Sobre las imágenes en la lírica (Al margen de un libro de Vicente Huidobro)", de 1916:

"las metáforas [...] no tienen otro valor que el de un medio de expresión indirecto de lo que carece en el lenguaje ómnibus de expresión directa. [...] Silenciar los nombres directos de las cosas, cuando las cosas tienen nombres directos, iqué estupidez! Pero [...] hay hondas realidades - cursiva nuestra - que carecen de nombre y que el lenguaje que 
empleamos para entendernos unos hombres con otros sólo expresa lo convencional, lo objetivo -entendiendo aquí por objetivo lo vacío de subjetividad, es decir, los términos abstractos en que los hombres pueden convenir por eliminación de todo contenido psíquico individual. Los buenos poetas son parcos en el empleo de metáforas; pero sus metáforas, a veces, son verdaderas creaciones" (ibid.: 781).

$\mathrm{Y}$ es que la lengua se sustancia en formas, en arquetipos perceptivo-intelectivos, que se sueldan a los significantes verbales, como lo otro inevitable o contrarreferencia, para hablar de lo otro, en el horizonte de la referencialidad utópica, formal o arquetípica -dentro del simulacro del máximo de alejamiento de la lengua con respecto al mundo extraverbal-, o en el horizonte más concreto de la referenciación tópica, concreta o individual -dentro del simulacro del máximo de aproximación de la lengua en relación con el mundo extraverbal concreto--.

Lo cual se puede orientar en un sentido contradictivo o ajeno a las expectativas de la memoria sociosemiótica integrada en su generalidad, como ocurre con los quid pro quo, los malentendidos, los equívocos, de los que se sirve el sofista, al decir de Aristóteles -"De los nombres, los equívocos le son útiles al sofista, pues en ellos están sus artimañas"-.

3. Todo ello, como señalamos en "Nuestro hablar: proceso pragmáticamente no exento" (1980: 13-20), no puede ser ajeno a la operación verbal ni a la memoria de las operaciones verbales habidas. Y esto es lo que podemos observar en los planteamientos de Theodor W. Adorno (1941, según En tierra de nadie. Theodor W. Adorno: una biografia intelectual, de Stefan Müller-Doohm (2003). [Traducción de R. H. Bernet y R. Gabás], Herder, Barcelona, págs. 404-405):

Le preocupaba saber qué idioma había de ser el más adecuado para el pensamiento crítico, que se entendía como antipositivista y antiidealista. En su primera reacción escrita a las consideraciones especulativas de Horkheimer, Adorno opuso que el desmoronamiento de la lengua era incontenible. Según decía, ese desmoronamiento debía comprenderse como expresión de la impotencia del sujeto frente a la superioridad de las fuerzas de las circunstancias sociales. El hecho de que la violencia de los hechos se haya vuelto de semejante forma en un espanto, de que toda teoría, y aun la verdadera, opere como una burla, [piénsese al respecto los anticipatorios planteamientos de Goethe al contraponer teoría a vida] ha marcado a fuego, como una señal, el órgano de la misma teoría, el lenguaje (ibid.:404).

Le preocupaba el problema de si la lengua tenía un estatus trascendental, si era más que un medio para la descripción del mundo y para llevar a cabo acciones, si la verdad y la razón debían presuponerse en todo hablar. Tenía una interesantísima intuición del lenguaje, para la que halló una expresión muy clara: "Hablarle a uno significa, en el fondo, reconocerlo como posible miembro de una futura asociación de hombres libres. Hablar establece una relación común con la verdad $\mathrm{y}$, por ello, la aceptación íntima de la existencia ajena a la que se habla y, propiamente, la de todas las existencias en su posibilidad". Al parecer, Adorno no reconocía el razonamiento original de Horkheimer, el potencial innovador de sus reflexiones filosóficas sobre el lenguaje, puesto que, en su réplica epistolar, que redactó de inmediato, invirtió los intentos de reflexión de su interlocutor. La idea directriz de su propia relación con el lenguaje era la perspectiva más bien ortodoxa de la preformación social, su cosificación. Por eso, interpretó el reconocimiento de Horkheimer acerca del potencial racional de la lengua como simple desciframiento del "carácter antagónico de 
toda lengua existente hasta ahora. [...] Si la humanidad no es todavia hoy mayor de edad, esto significa literalmente que, hasta el día de hoy, aún no ha aprendido a hablar". Sin embargo, en breve pasaje de su carta aparecía una idea que se acercaba a las especulaciones de Horkheimer. Según escribía Adorno, le resultaba difícil "entender que un hombre que habla pueda ser un canalla o que pueda mentir". Imaginar esto contradecía simplemente la "reivindicación de verdad del lenguaje". Partiendo de ahí, decía Adorno: "En el enunciado "un ser humano ha hablado y, por tanto, ha de ser verdad", enunciado del que toda sensatez se burla, se esconde justamente la verdad que esa sensatez traiciona. (págs. 405-406).

En la nota 469 (ibid.:405) nos dice el biógrafo Stefan Müller-Doohm:

Bajo el título de "Racionalidad comunicativa", Jürgen Habermas investigó cuarenta años más tarde de un modo sistemático la pregunta por las condiciones de validez asociadas con el lenguaje, que han de hacerse efectivas en el discurso < de esto se trata en lo que aquí planteamos y venimos planteando desde nuestra propia reflexión sobre el comportamiento verbal>. Con ello fundamentó el llamado "giro lingüístico" [linguistic turn] de la teoría crítica. En Verdad y justificación [Wahrheit und Rechtfertigung] (1999:110) dice lo siguiente acerca del concepto central de la racionalidad comunicativa: "No es la lengua per se, sino la utilización comunicativa de las expresiones lingüísticas la que posee una peculiar racionalidad [...] Esta racionalidad comunicativa se expresa en la fuerza unitiva del discurso orientado a la comprensión, que al mismo tiempo garantiza a los hablantes un mundo de la vida intersubjetivamente compartido y, con ello, el horizonte dentro del cual pueden referirse todos a un mismo y único mundo objetivo.

La selección léxica es fundamental en el proceso dinámico de cualquier discurso, sobre todo en el decir esencial como el poético, donde el arte estético-creativo del poeta sobresale en la selección y tejido de las palabras, palabras plenas, autosémicas, si se quiere: "Más raro es ser el hombre que entrelaza/ Palabras en un cuarto de su casa" dice de su yo poético Jorge Luis Borges. En efecto, en el discurso el flujo verbal intersujetivo lo es básicamente de palabras significativas, que el hablante entrelaza selectiva e intelectivamente en orden a obtener un conjunto verbal en sí mismo significativo, en la medida en que las palabras que figuran en él han sido seleccionadas, proferidas con preferencia frente al resto o distinguidas frente a otras, y en esto, precisamente, estriba su plus significativo-discursivo, puesto que distinguir y significar vienen a ser una y la misma cosa.

4. Las secuencias oracionales pueden ser co-ordinadas, según la condición de los segmentos y operadores discursivo-verbales explícitos, y meta-ordinadas, en función de los implicaturas o presupuestos entrañados en las secuencias verbales concretas. A este propósito, me remito a lo señalado en otro lugar (1979:39-40):

Piénsese, por ejemplo, en el siguiente texto tomado de El Lazarillo de Tormes: "Escapé del trueno y di en el relámpago. Porque era el ciego para con éste un Alejandro Magno, con ser la misma avaricia como he contado".

Es un enunciado eminentemente hiperotáctico o clasemático, apto para recubrir múltiples enunciados específicos subsiguientes. De suyo esa "sintaxia" o enunciado memorizado puede ser parafraseado o entendido como: 
"Escapé de lo malo y di en lo peor", que igualmente puede ser aplicado a múltiples situaciones contextuales. No sabemos siquiera si se trata de un individuo o de un objeto maligno cualquiera. La heterosemia en orden específico es manifiesta. Se precisan otros enunciados concretizadotes, reductores de la extensión máxima. Esta función la cumple el enunciado siguiente:

"Porque era el ciego para con éste un Alejandro Magno..." Si acabara ahí el texto, tendríamos ya una concreción o reducción de la suma extensión anterior, pero todavía estaríamos ante enunciados altamente clasemáticos. En efecto, el trieno o lo malo, tratándose del ciego, podría ser tanto su impotencia visual o ceguera, su malicia característica como su mezquindad o avaricia. El clérigo de quien tenemos noticia en el texto inmediato anterior, sería peor que el ciego en cualquiera de estas direcciones, connotadas por igual. Y esa función selectora de los diversos sentidos posibles viene ejercida por la prolongación efectiva del texto: "con ser la misma avaricia como he contado".

"Escapé del trueno y di en el relámpago."

$/$ maldad/ $<\mathrm{A}\rangle\langle\mathrm{vs}\rangle\langle\mathrm{B}\rangle$ /empeoramiento/

"Porque era el ciego para con éste un Alejandro Magno..."

/maldad del ciego superada por la del clérigo/

/ceguera/ /avaricia/

/astucia malintencionada/

"con ser la misma avaricia como he contado".

/a avaricia del ciego es superada por la del clérigo/

Con lo cual, Escapé del trueno y di en el relámpago viene a significar, tras la acumulación de rangos superiores, "Salí de un amo-miseria y encontré otro archimiseria".

El análisis específico de las construcciones oracionales hiperotácticas que realizamos posteriormente (1982:101-124) pone de manifiesto (ib.:103-104) que

la hiperotaxis es un procedimiento de nexuación oracional que se estructura sobre la base de dos momentos fundamentales:

1. Momento paratáctico, en el que se plantean los dos enunciados asertorios en torno a un núcleo verbal con valores comunes en ambos enunciados subyacentes, bien por identidad especifica, isosemia lexemática, bien por identidad semémica, isosemia achisemémica, bien por identidad genérica o isosemia clasemática.

II. Momento hiperotáctico, o tensión dialéctica [...] que consiste en instrumentar los asertos paratácticos subyacentes como argumentos de una aserción superior (hiperotaxis) o aserción de aserciones, que domina y engloba dicho proceso nexual en su integridad.

Bien es cierto que la materia verbal fundamental del pasaje de la inmortal novelita no es otro que

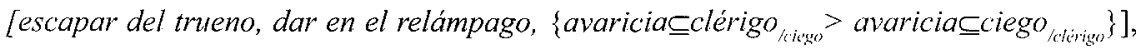

que son los ejes fundamentales o elementos paratácticos inherentes a la correspondiente configuración estético-discursiva de dicho texto; pero más allá de esos elementos se establece hiperotácticamente una nueva respectividad adherente desde los datos o instrucciones condicionadas por la discursividad de la materia verbal seleccionada, que es la que es y no otra, en función del marco enunciativo-interlocutivo, que nos da pie para entender que las asociaciones o predicciones perceptivo-intelectivas inherentes a la materia verbal convergente en el núcleo 
temático-paratáctico $\langle\mathbf{A}\rangle$ es sociosemióticamente inferior a las identificadas por el núcleo temático-paratáctico $<\mathbf{B}>$, en el sentido de que [la avaricia del clérigo de Maqueda era superior a la del ciego y, consecuentemente, Lázaro, al entrar a su servicio, fue de mal en peor].

5. La palabra como la pintura repercute sobre los sentidos, los impregna de su valor entitativo y los encamina hacia su configuración compositivo-intelectiva resultante. Pintar como computar verbalmente viene a ser lo mismo que "poner a la vista, presentar, hacer ver", decir, en suma, lo que se considera de interés intersubjetivo, dejando en silencio el resto, por irrelevante, insignificante o voluntariamente silenciado.

Los elementos seleccionados para un discurso dado están llamados a entrar en una serie de relaciones, desde las meramente paratácticas -coordinadas-, que se imponen de suyo, a las hipotácticas, endotácticas, diatácticas o hiperotácticas-subordinadas, intraordinadas, interordinadas o hiperordinadas, según planteamos ya (1982:171)-, que se condicionan entre sí, en diverso grado, desde los valores paratácticos básicos o fundamentales, que actúan como garantía de los elementos que configuran el conjunto discursivo resultante.

La distribución de las palabras en un texto dado, como la de los colores de un lienzo o cuadro, no sólo nos hace ver a través de los elementos, palabras o colores, sino que se nos ofrece al diálogo perceptivo-intelectivo intersubjetivo como conjunto globalmente configurado en cuanto composición o resultante de sus elementos, en sí mismos y también en cuanto compuestos de otros elementos más simples. No hay más que poner unas frases junto a otras, unas palabras junto a otras, unos trazos o colores junto a otros, para que del conjunto tanto como de sus elementos surjan las pautas virtuales de virtuales lecturas o percepciones en cuanto réplicas inconclusas perceptivo-intelectivas que toda operación verbal trae consigo.

Partiendo de los enunciados tópicos como "primum vivere, deinde philosophare", "cogito, ergo sum", etc., podemos reflexionar de acuerdo con el siguiente esquema de posibilidades de análisis:

1. selección de elementos o momento paratáctico de la operación verbalcsintaxis cognitivo-prediscursiva :

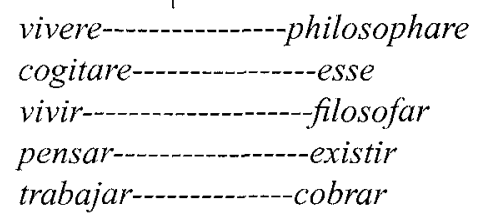

2. orden estructural subyacente a los elementos seleccionados $\subset$ nexuación subyacentecsintaxis cognitivo-prediscursiva ${ }_{2}$ :

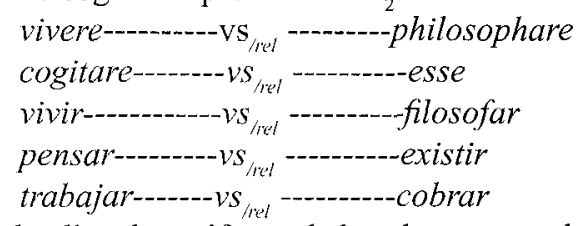

3. orden lineal manifiesto de los elementos seleccionados $\subset$ nexuación manifiesta $\subset$ sintaxis cognitivo-discursivacconstrucciones morfosintácticas: 
cogitare sequitur esse ergo-

primero vivir, después filosofar -luego-más tarde

a continuación pensar, *después ser luego-

*más tarde------

primero trabajar, luego cobrar después$\varnothing-$

No es que luego no esté emparentado con más tarde, después, a continuación, etc. Lo que ocurre es que su especificidad inferencial, en los casos que tal sentido surge, está condicionada no únicamente por su significado o valor sistemático-lingüístico elemental, sino por los esquemas sintagmáticos o interfrásticos de los que se tiene memoria o noticia. En este ámbito existe el sentido inferencial de luego; pero tal sentido surge del conjunto sintagmático, dado el enfrentamiento originario establecido o establecible por la propia operación selectivo-discursiva que enfrenta dialécticamente las palabras PENSAR y SER, COBRAR y TRABAJAR, etc.

En cierto modo, el proceso ontogenético por el que llegamos al uso cabal de la dinámica interoracional, observable en el proceso de aprendizaje de la lengua materna así como en el de otras lenguas, presenta un primer momento de orden paratáctico, para pasar, ulteriormente, a la elaboración cognitivo-interactiva de la materia verbal o segundo momento paratáctico-hipotáctico, en el que el hablante, dueño de su lengua y de su pensamiento, da cauce expresivo-manifestativo a todo tipo de elaboración cognitivo-discursiva, puesto que a los conceptos, a los pensamientos elaborados, a las significaciones no sólo les nacen palabras, como señalaba M. Heidegger (1974:182), sino también todo tipo de esquemas, estrategias y pautas discursivas.

El orden lineal, en la medida en que traduce un orden estructural o esquemas cognitivos elementales o primarios, se resuelve paratácticamente en forma de flujo o sucesión de unos elementos verbales junto a otros:

\section{Existo primero y pienso después $\Rightarrow \quad$ Primero existo y luego pienso \\ Existo y pienso \\ Existo, pienso}

En cambio, cuando el orden lineal traduce un orden estructural o esquemas cognitivos complejos, para dar cuenta de configuraciones cognitivo-metadiscursivas complejas, se resuelve hipotácticamente, en toda su variedad sintagmático-discursiva:

Pienso y reflexiono sobre mi existir $\Rightarrow$ Si pienso, es porque existo

Si pienso, existo

Pienso, luego existo 


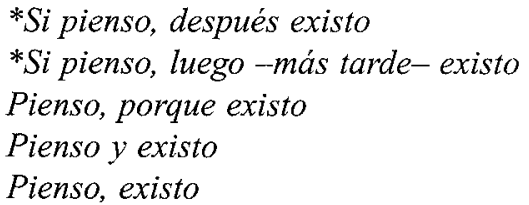

De modo que, en analogía con los planteamientos de L. Tesnière, es el orden estructural, lingüístico-cognitivamente subyacente, el que elige el orden lineal lingüístico-discursivo en el comportamiento textual, que será no marcado o marcado, en la medida en que se cumplan expectativas cognitivo-discursivas simples o complejas, como fundamento del sentido global dominante, que será paratáctico, en el nivel lineal y estructural, o, por el contrario, será no meramente paratáctico o hipotáctico -en cualquiera de las variantes de esta genérica denominación de las variedades no paratácticas-, en el nivel subyacente o estructural, sea cual sea la solución manifestativo-lineal elegida, que podrá presentar actualizaciones paratácticas o hipotácticas, más allá de la solución interoracional elegida, que puede darse desde $\emptyset$ a cualquier tipo de interrelación interoracional explítica:

Tanto criticarle, para ser su amigo

---importunarle,

------insistirle,

Hizo muchas cosas, pero estaba enfermo

, para estar

, aunque estaba-

6. La parataxis es fruto de la percepción. Se impone por analogía con la disposición de las formas perceptibles que nos envuelven por doquier.

Es el ordenamiento sintagmático de la inmediatez, como punto de partida para ulteriores reflexiones o comportamientos, o como resultado de elaboraciones conceptuales complejas. Piénsese, por ejemplo, en el esquemático texto destinado a ser pegado en los vehículos mal estacionados en el campus de la Universidad de Alicante, que aparece estructurado paratácticamente del modo siguiente:

Encabezamiento del texto:

$$
\text { Icono }+\begin{aligned}
& \text { Universitat d'Alacant } \\
& \text { Universidad de Alicante }
\end{aligned}
$$

Cuerpo:

- Rogamos estacionen sus vehículos en los lugares destinados para ello

- Tomamos nota de su matrícula

- En caso de reincidencia, su vehículo será retirado por la grúa

Pie:

SERVICIO DE SEGURIDAD + sello de la Universidad 
A nadie se le oculta que a una disposición lineal paratáctica tan elemental subyace una planificación programático-estructural compleja, que aparentemente sólo informa, pero persuade $y$, en última instancia, conmina.

7. La hipotaxis es fruto de la intelección. Se impone tras la elaboración mental de los datos perceptivos, donde, por caso, percibida una situación $<A>-$ el contagio de paludismo- $y$ la situación ulterior $\langle\mathrm{B}>-$ la muerte de la persona contagiada de paludismo-, inducimos, en disposición lineal no marcada, simétrica, o marcada, asimétrica, una relación global en la que interactúan las dos situaciones tenidas en cuenta:

\section{Ha muerto porque se contagió de paludismo}

Ha muerto de paludismo

Ha muerto; se contagió de paludismo

En la disposición sintagmática de los segmentos verbales se da cuenta del emparejamiento convencional o metafórico de las palabras que pueden presentarse en las más dispares situaciones, desde las más esperadas a las más sorprendentes, según la motivación pragmático-cognitiva de la selección de la materia verbal convocada a formar parte de la configuración discursiva de un texto dado.

8. Cualquier corte de lengua que se realice en su dinámica filogenética puede dar una imagen de los empleos paratácticos e hipotácticos en función de la madurez mental o sociocultural de los hablantes considerados; si bien -pese a las prevenciones de T. W. Adorno anteriormente mencionadas o precisamente por ellas, en cuanto a latente aspiración- la madurez mental de la comunidad hablante está garantizada o presupuesta, en el sentido moral de lo mejor a lo que utópicamente aspira cualquier comunidad en cualquier momento de su existencia, como se refleja entre otros en E. Coseriu (1995) y J. Marías (1996).

En todo caso, se pueden encontrar razones para las soluciones interoracionales paratácticas e hipotácticas en función del marco interlocutivo, que encamina el discurso por los diversos cauces tipológico-textuales. Los textos descriptivos -inventarios, relaciones, listados, resúmenes, esquemas, etc.-, los normativos -recetarios, instrucciones de uso, contratos, convenios, testamentos, reglamentos, códigos, constituciones, etc.- y los dialógicos -conversaciones, entrevistas, discusiones, llamadas telefónicas, etc.- presentan una afinidad paratáctica evidenciable, por no hablar de la gran disponibilidad paratáctica de la escritura poética de configuración estrófico-versal, más allá de los grandes mamotretos paratácticos que son los diccionarios y enciclopedias, listados terminológicos, etc. En cambio, los textos expositivo-argumentativos -debates, planteamientos, exposiciones orales o escritas, etc.- y narrativos son más proclives al predominio hipotáctico.

9. En el perfil ontogenético cabe percibir las diferencias de uso paratáctico e hipotáctico. Su periodicidad, frecuencia y uso en función de las edades psicolingüísticas así como según las modalidades diafásicas son evidenciables diversas frecuencias de parataxis e hipotaxis, en un orden de gradación de menor a mayor madurez lingüística o de menor a mayor complejidad intelectiva. En el aprendizaje de una lengua extranjera, análogamente, también se 
puede observar la gradación planteable en la evolución psicolingüística dentro de la lengua vernácula.

10. A lo largo de esta reflexión, hemos partido de la hipótesis de que los diversos procedimientos de relación interoracional hipotáctica son posteriores a la parataxis en la filogénesis y en la ontogénesis. Todo periodo hipotáctico puede ser reconducido a la parataxis, pero no a la inversa. Muchos de los valores asignados a los operadores o marcadores del discurso no excluyen la perspectiva paratáctica en el proceso hipotáctico integrado de gran parte de las construcciones hipotácticas, cuyo sentido último deben al incremento significante condicionado por la operación sintagmático-discursiva en su integridad. Más allá del proceso filo-ontogenético, tanto la parataxis como la hipotaxis son procedimientos opcionales al servicio del hablante en función de sus intereses discursivo-textuales.

\section{Referencias bibliográficas}

Aristóteles (1971): Retórica. (Edición del texto con aparato crítico, traducción, prólogo y notas por A. Tovar). Instituto de Estudios Políticos, Madrid.

Chevalier, J. C. y Molho, M. (1986): "De l'implication: esp. pues fr. puis", Travaux de Linguistique et de Littérature, XXIV, 1, págs. 23-34.

Coseriu, E. (1995): "La lingua literaria", Revista de Filología de la Universidad de Vigo, 15-25.

Machado, A. (1973): Obras. Poesía y Prosa, Losada, Buenos Aires.

Marías, J. (1996): Tratado de lo mejor. La moral y las formas de la vida. Alianza Editorial, Madrid.

Müller-Doohm, S. (2003): En tierra de nadie. Theodor W. Adorno: una biografia intelectual. (Traducción de R. H. Bernet y R. Gabás). Herder, Barcelona.

Ortega y Gasset, J. (1983): Obras completas. Alianza Editorial, Madrid.

Ramón Trives, E. (1979): Aspectos de semántica lingüístico-textual. Istmo, Madrid.

Ramón Trives, E. (1982): Estudios sintáctico-semánticos del español $-I$ - La dinámica interoracional, Godoy, Murcia.

Ramón Trives, E. (2003): "A vueitas con el SI deíctico-aseverativo y su polivalencia sintagmática en castellano", Estudios ofrecidos al profesor José Jesús de Bustos Tovar, Editorial Complutense, Madrid, págs. 135-156.

Rousseau, A. (1986): "L'implication en langue naturelle et en logique", Travaux de Linguistique et de Littérature, XXIV, 1, págs. 35-57.

Trujillo, R. (1998): Principios de Semántica Textual. Arco/Libros, Madrid.

Unamuno, M. de (1969): Obras Completas, VI. Escélicer, Madrid. 